BULLETIN Bulletin hispanique

HISPANIQUE Université Michel de Montaigne Bordeaux

112-1 | 2010

Actes du Colloque « langue, littérature, littéralité »

\title{
Rafael Alarcón Sierra, Luis Felipe Vivanco: contemplación y entrega
}

Ayuntamiento de Madrid, 2007

Nicolás Fernández-Medina

\section{(2) OpenEdition}

\section{Journals}

Edición electrónica

URL: http://journals.openedition.org/bulletinhispanique/1206

DOI: 10.4000/bulletinhispanique.1206

ISSN: $1775-3821$

\section{Editor}

Presses universitaires de Bordeaux

Edición impresa

Fecha de publicación: 1 junio 2010

Paginación: 454-458

ISBN: 978-2-86781-692-5

ISSN: 0007-4640

\section{Referencia electrónica}

Nicolás Fernández-Medina, «Rafael Alarcón Sierra, Luis Felipe Vivanco: contemplación y entrega ».

Bulletin hispanique [En línea], 112-1 | 2010, Publicado el 04 enero 2013, consultado el 23 septiembre 2020. URL : http://journals.openedition.org/bulletinhispanique/1206 ; DOI : https://doi.org/10.4000/ bulletinhispanique. 1206 
establecen -demostrando un conocimiento imprescindible de la tradición poética francesa asimilada desde sus inicios literarios por Manuel Machadoy que abren nuevas posibilidades de indagación muy distintas y amplias. Para los filólogos alcanforados que trivializan el trabajo de quienes nos dedicamos al estudio y edición de la poesía contemporánea, el de Rafael Alarcón Sierra es uno de los mejores ejemplos que cabe proponerse como de máxima especialización, tanta como la requerida para estudiar y anotar textos medievales o del Siglo de Oro.

\section{BIBLIOGRAFÍA CITADA}

Rafael Alarcón Sierra, La poesía de Manuel Machado: Alma, Caprichos, El mal poema (estudio y edición crítica), Zaragoza, Prensas Universitarias de Zaragoza (Serie Microfichas), 1997.

- (ed.) (1997). “Gloria... jla que me deben!”, Manuel Machado (1947-1997)», Insula, 608-609.

- (ed.) (1999). Manuel Machado, Cuentos completos, Madrid, Editorial Clan.

- (1999). Entre el modernismo y la modernidad: la poesía de Manuel Machado (Alma y Caprichos), Sevilla, Diputación Provincial de Sevilla.

- (ed.) (2000). Manuel Machado, Alma. Caprichos. El mal poema, Madrid, Castalia.

- (ed.) (2000). Manuel Machado, Impresiones. El modernismo (Artículos, crónicas y reseñas, 1899-1909), Valencia, Pre-Textos.

- (2008). El mal poema de Manuel Machado. Una lírica moderna y dialógica, Madrid, Biblioteca Nueva.

\section{Almudena del OLMO ITURRIARTE}

Rafael Alarcón Sierra, Luis Felipe Vivanco: contemplación y entrega, Madrid, Ayuntamiento de Madrid, 2007.

En su último libro Luis Felipe Vivanco: contemplación y entrega (2007), editado por la Imprenta Artesanal del Ayuntamiento de Madrid en una colección dirigida por Mario Hernández, Rafael Alarcón Sierra (director del Departamento de Filología Española, Universidad de Jaén) nos revela la trayectoria vital y poética de este poeta casi olvidado en las letras españolas. Como va siendo común con Alarcón Sierra -autor de las monografías Entre el modernismo y la modernidad: la poesía de Manuel Machado (Alma y Caprichos) (1999, Premio Archivo Hispalense) y Juan Ramón Jiménez. 
Pasión perfecta (Espasa-Calpe, 2003), entre otras muchas publicaciones- el libro es de primer orden tanto en su crítica como en su bibliografía, e incluye además una docena de fotografías del poeta en diferentes épocas, algunas nunca antes publicadas. El libro de casi doscientas páginas viene emparejado con una antología ilustrada por Gustavo Torner, que recorre desde «Memoria de la plata» (1929) hasta el póstumo Prosas propicias (1976). La antología contiene una selección representativa de setenta y un poemas del quehacer poético de Vivanco en clásicos como «Fábula del gran Fausto», "Me asomo a tu belleza», "Mi canción de la torre más alta», "A caza», "Salmo improvisado de mis cuarenta años», "El descampado» y «La condición canina», y es un suplemento indispensable a la crítica de Alarcón Sierra.

El libro de Alarcón Sierra está dividido en varias secciones que avanzan cronológicamente por la vida y obra de Vivanco, desde su primera infancia en Madrid entre 1907 y 1921, hasta las décadas de los setenta y ochenta, época en la que su viuda María Luisa Gefaell y su hija Soledad intentan divulgar sus diarios (esfuerzo que culmina con la publicación de Diario (1946-1975) en Taurus en 1983). Lo que yace en el meollo del libro es recuperar la obra fundamental de Vivanco: una obra comúnmente relegada a un par de poemarios y hechos vivenciales dentro del canon literario español actual. Es por ello que el libro abre con en el siguiente interrogante: "iPor qué Vivanco es un poeta apenas leido?»

Las respuestas son varias en este libro y abarcan aquellos límites y prejuicios asociados con conceptos generacionales, historiográficos, filológicos y políticos, de la labor crítica propiamente dicha. «La crítica filológica más anquilosada", nos dice Alarcón Sierra, "no suele entender ni perdonar que un poeta salte alegremente las barreras y etiquetas que se le ponen en un momento dado» (10). Y Alarcón Sierra va sondeando sistemáticamente estos límites y prejuicios en la obra de Vivanco (y desmitificándolos, en cierta medida, especialmente en términos de no sólo la gran profundidad líricaemotiva de su poesía, sino también la afiliación falangista del poeta), que han perjudicado a lo largo de los años su plena recepción. Lo que ha puesto de manifiesto Alarcón Sierra -aportando de paso datos inéditos del poeta y lo que promete ser una nueva vitalidad analítica a aquellas intuiciones críticas que quedaron, en muchas instancias, meramente reseńadas por lectores como Aranguren, J. L. Cano, G. Diego y R. Gullón- es que Vivanco, antes que nada, era poeta, pero un poeta pensador que se puede ubicar dentro de la honda línea contemplativa de un Rilke, Vallejo, o A. Machado, en cuanto a sus preocupaciones existenciales fijadas en aquello que don Antonio denominó «lo esencial humano». Es así, por ejemplo, cómo los objetos de todos los días, las rutinas diarias, y las pequeñas revelaciones del ser en algún 
momento dado, asumen formulaciones trascendentes para Vivanco.

Aunque se trata de un libro compacto y minucioso, es obvio que, ante todo, Alarcón Sierra quiso reavivar la voz de Vivanco para su lector. En cada página es imposible esquivar la voz del poeta; bien sea aquella voz más intimista de sus diarios, o aquella más seca y directa de su crítica, o quizás aquella más sugestiva de su poesía. En este aspecto, el libro recrea, sin duda alguna, la figura más humanizada de Vivanco dentro de la crítica actual. Es desde este punto de entrada como mejor se entienden, por ejemplo, las influencias literarias del poeta y cómo afectaron su visión ontológica-poética (influencias que incluyeron a Rilke, Vallejo, Cernuda, A. Machado, Claudel, Jammes, Neruda, Trakl, etc.), las razones que le motivaron a llevar a cabo sus múltiples proyectos críticos y narrativos a lo largo de los años (como su premiada Introducción a la poesía española contemporánea de 1957, o sus libros de memorias La humildad de ser poeta -libro inédito salvo algunos fragmentos-, y Los ojos de Toledo publicado en 1952), o la afiliación política al falangismo del poeta.

En cuanto a la cuestión política, le dice Vivanco a Victoriano Rodríguez en 1972: "Poco antes de la guerra, mi desengaño de la República y la reconciliación con la familia, me llevó a un intento fallido de pasarme a derechas» (33). Este «intento fallido» al que se refiere Vivanco, sin embargo, duró - más o menos- hasta finales de la década de los sesenta, pero vemos que a partir de 1945 comienza el poeta a distanciarse paulatinamente de la Falange, optando "por una posición discreta, de exilio interior, negándose a colaborar en las actividades oficiales del régimen» (51). Este proceso de lenta retracción, de exilio íntimo y de desapego «discreto», como bien señala el libro, le causó varios estragos a Vivanco. No sólo tuvo que lidiar con la Falange en el ámbito político y laboral (consciente el régimen de su «tibia adhesión»a sus ideales), sino que tuvo que sentir, por lo que emerge fragmentariamente al cabo de los ańos en sus diarios y en algunos poemas como "Descansillo", «Negocios», y «La condición canina» en Prosas propicias, una sensación de honda culpa y remordimiento que brotó de su conformidad política y su silencio. "[H]ay una denuncia moral y una sátira», propone Alarcón Sierra, "muy intensa [en Prosas propicias] de todos los vicios de la sociedad franquista y de sus diversos estamentos» (145). En el poema «Infantes» de dicho poemario, por ejemplo, queda claro cómo quedó Vivanco, en cuerpo y alma, después de su larga experiencia falangista:

Camino y me alucino con el sepulcro a cuestas

Camino como un huésped mutilado celebrado y

equívoco por dentro pero sucio por fuera de

tanta retirada y oposición tardía de tanto 
maldecir el predominio la enjundia y los valores indudables de las tapias ajenas (15-20)

Y al margen de cómo se ha apreciado o ignorado la poesía y figura de Vivanco a raíz de su posición política (para algunos un tema decisivo, puesto que es verdad que nunca se opuso a la Falange frontalmente cuando bien podría haberlo hecho), esta faceta complicada del poeta poco se entendería en sus más amplias dimensiones sin los descubrimientos del libro de Alarcón Sierra.

Lo que se desprende con más nitidez de los análisis poéticos del libro es el proceso de depuración conceptual y poética a la que se somete Vivanco. Desde sus primeros ejercicios neorrománticos dedicados al amor en Cantos de primavera de 1936 (en los que predominan «un lenguaje bastante elevado, abstracto y genérico, que no hace apenas referencia a realidades concretas o circunstanciales»), hasta la obra más profunda posterior que culmina con sus Prosas propicias (en la que imperan los misterios del hombre en su pleno contexto vital, y en donde queda plasmada no sólo esa creciente preocupación por el tiempo de Vivanco, sino también la viva presencia de Dios), advertimos una continua búsqueda de una expresión lírica más inmediata, sencilla, y cotidiana. Después de leer a fondo la obra de A. Machado, Unamuno y Rilke, a principios de la década de los cuarenta, Vivanco se propone seguir un nuevo derrotero lírico más íntimo y trascendente: «[quiero] escribir un libro hacia dentro y hacia el otro mundo [...] poemas del dios más intenso y menos preciso" (49). En 1949 aparece Continuación de la vida, que en buena medida da forma a este nuevo impulso creador. De esta fecha en adelante, Vivanco puliría su voz poética inagotablemente, y para 1957, creerá firmemente que «la poesía consiste en estar más cerca siempre: más cerca de una realidad» (82).

Pero esta realidad de Vivanco, como nos la reconstruye hábilmente Alarcón Sierra, no es la realidad "comprometida» de los poetas sociales, sino una realidad que se relaciona más -al menos en espíritu e intimismo- a esa existencia heideggeriana del ser-en-el-mundo (y aquí conecta Vivanco, aunque tangencialmente, con algunos de los propósitos de la promoción del 50). Según Alarcón Sierra, en su Introducción a la poesía española contemporánea, Vivanco «sigue muy de cerca a Heidegger en varios aspectos [...y] asume la afirmación central de [su] estética ontológica: "la poesía es la fundación del ser en la palabra" " (83). Luego publicaría Vivanco Memoria de la plata en 1958 (un poemario algo experimental que transforma completamente su escritura, la abre hacia nuevas perspectivas), y Lecciones para el hijo en 1961, poemarios decisivos en su obra que dejan paso a los poemas que se 
reunirán en Prosas propicias, su obra prima. Y toda esta trayectoria poética nos la presenta Alarcón Sierra con gran soltura y sutileza, sin perder de vista nunca la cuestión contemplativa y humana que yace en los cimientos de la poesía de Vivanco. En otras palabras, este libro resume y deja claramente delineado cómo llega a ser poeta Vivanco, particularmente en términos de su ambiente sociohistórico y sus preocupaciones personales. A este respecto, habría sido incluso más completo el libro si hubiera dedicado Alarcón Sierra unas páginas más a los fundamentos filosóficos de la obra de Vivanco a través de aquellas figuras tan transcendentales en su pensar como lo fueron Unamuno, A. Machado, Heidegger y Zubiri, pero se entiende que abarcar estos gigantes del pensamiento hubiera requerido otro tipo de aproximación y hasta otro tipo de libro.

Para el lector o estudioso de la obra de Vivanco, Luis Felipe Vivanco: contemplación y entrega de Alarcón Sierra es una lectura fundamental. En este libro, acompañado de su antología poética con una muestra de los poemas más significativos del poeta entre 1929 y 1976, se encontrará tanto Vivanco el poeta como Vivanco el hombre. Y estas dos facetas, que en verdad son una sola, hacen que el poeta reviva en este libro y recobre algo del reconocimiento perdido hasta hoy.

\section{Nicolás FERNÁNDEZ-MEDINA}

Sables d'exil. Les républicains espagnols dans les camps d'internement au Maghreb (1939-1945), Andrée Bachoud \& Bernard Sicot (dir.), no spécial de : Exils et migrations ibériques au XX $\mathrm{XX}^{\mathrm{e}}$ siècle, $\mathrm{n}^{\circ} 3$ (nouvelle série), Université Paris Ouest Nanterre La Défense (BDIC/CERMI/ CRIIA). - Perpignan, Mare Nostrum, 2009, 316 p. - ISBN : 978-2-908476-72-9 EAN : 9782908476729

L'ouvrage dirigé par Andrée Bachoud et Bernard Sicot sur l'exil des républicains espagnols vers l'Afrique du Nord, pendant et surtout à la fin de la Guerre d'Espagne, vient combler un vide historiographique important.

La préface et les huit chapitres ont été confiés aux spécialistes de la question. Le livre s'ouvre sur un prologue de Christine Levisse-Touzé dont on connaît l'incontournable' L'Afrique du Nord dans la guerre, 1939-1945. Le but est de montrer comment cet exil vers l'autre rive de la Méditerranée, bien que très inférieur en nombre au grand exode que connut la France, éclaire d'un jour nouveau les grands enjeux du siècle dernier et en particulier le passage 